\title{
Atlas for the Blind, 1837
}

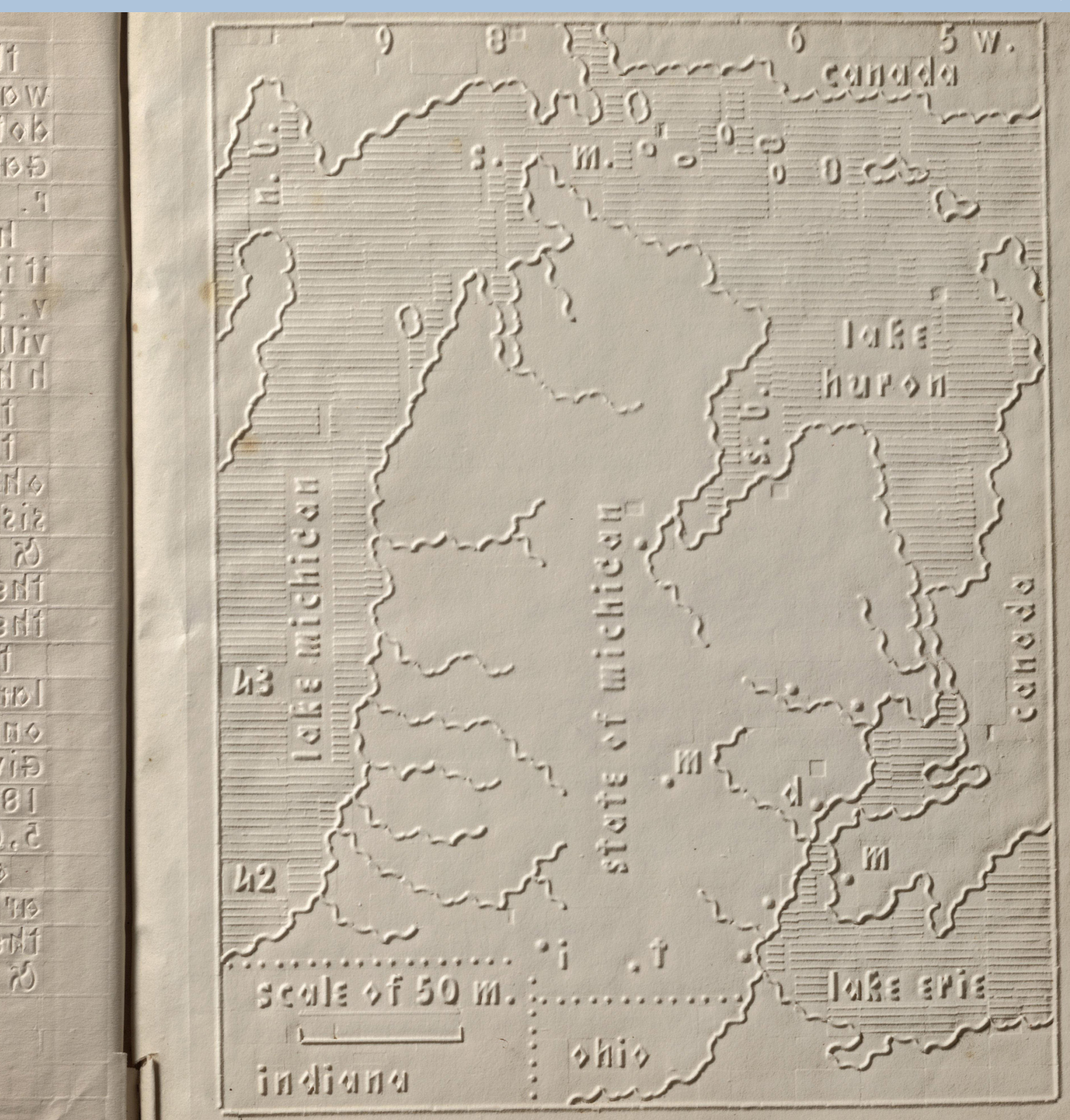

(c) $\$\left(\begin{array}{l}0 \text { by the author(s). This work is licensed under the Creative Commons Attribution-NonCommercial-NoDerivatives } \\ 4.0 \text { International License. To view a copy of this license, visit http://creativecommons.org/licenses/by-nc-nd/4 }\end{array}\right.$ 
THE Atlas of the United States Printed for the Use of the Blind was published in 1837 for children at the New England Institute for the Education of the Blind in Boston. Without a drop of ink in the book, the text and maps in this extraordinary atlas were heavy paper embossed with letters, lines, and symbols. To the best of our knowledge, this is the first atlas produced for the blind to read without the assistance of a sighted person. Braille had been invented by 1825 , but was not widely used until later. It represented letters well, but could not represent shapes and cartographic features.

Samuel Gridley Howe (1801-1876) was the founder and president of the New England Institute (later known as the Perkins Institute) and produced the atlas with the assistance of John C. Cray and Samuel P. Ruggles. Howe was the husband of Julia Ward Howe, the American abolitionist and author of the US Civil War song "The Battle Hymn of the Republic." He was a champion of people with disabilities and believed that blind youth could be taught geography through maps created with his special paper embossing process. In his introduction to the atlas, Howe notes that crude attempts had been made to create maps for the blind, but they used primitive methods of creating

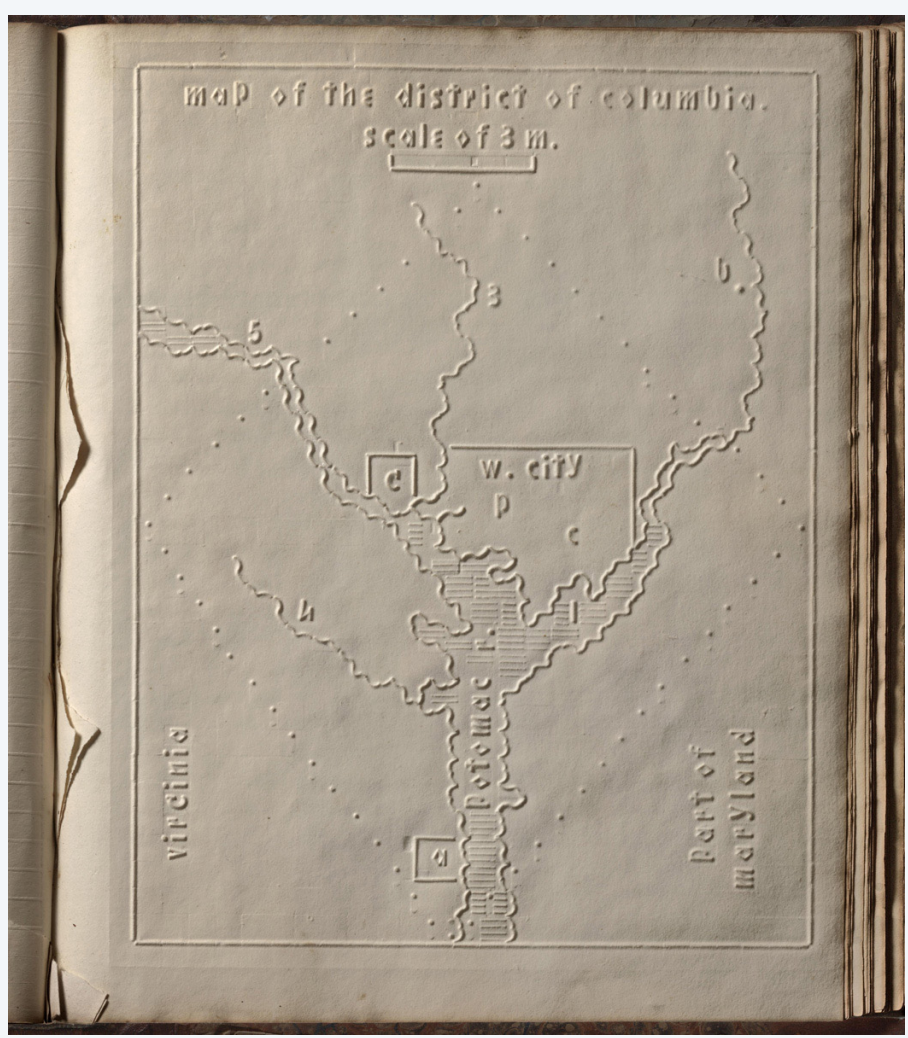

This map of the District of Columbia shows Washington (w. city), Georgetown (g), and Alexandria (a) as well as the President's house (p) and the Capital (c).

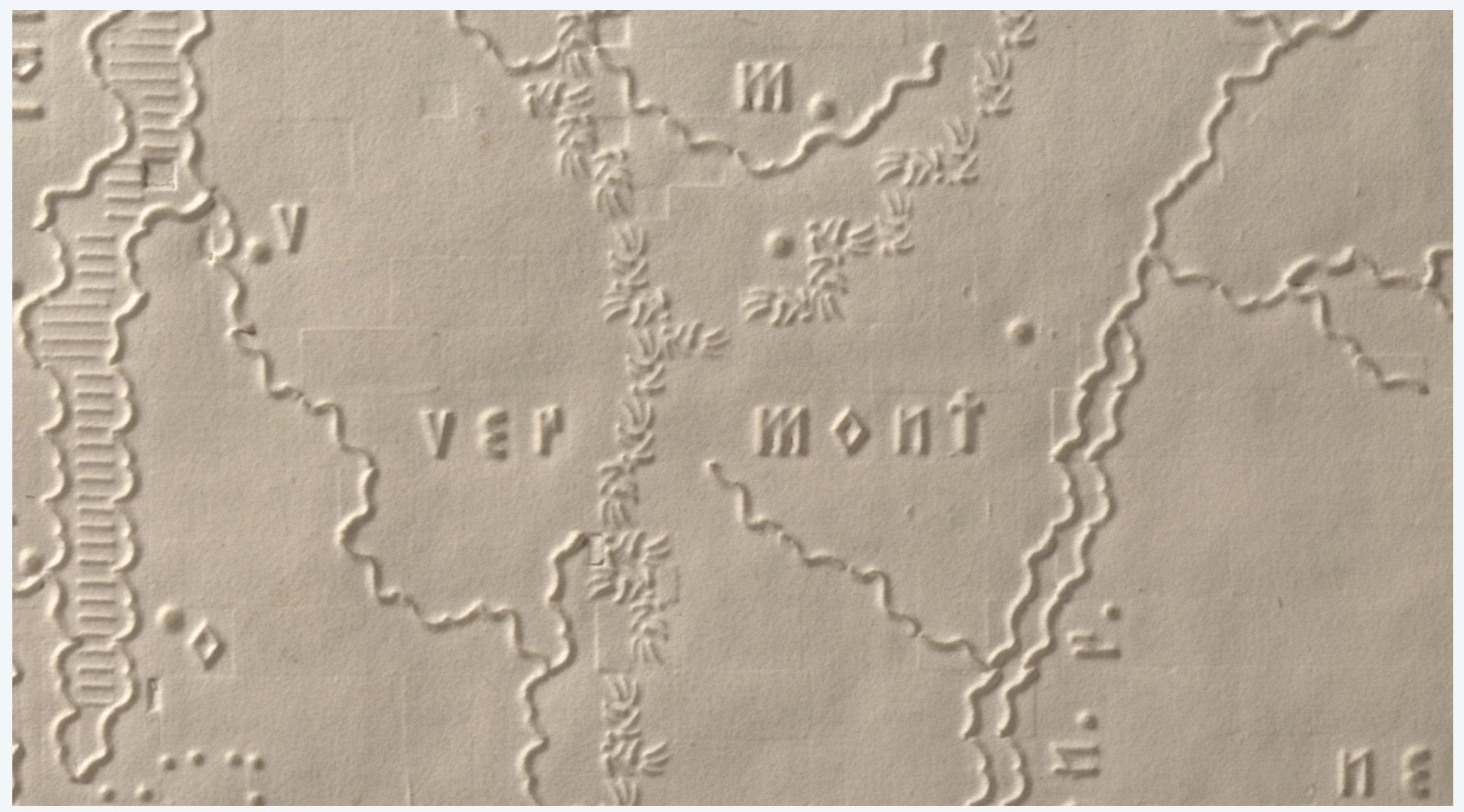

This enlarged view of the Vermont map shows the various symbols used as well as the impressions of the underlying blocks used in the embossing method. Mountains are shown as a series of short lines in this detail of the Green Mountains. 

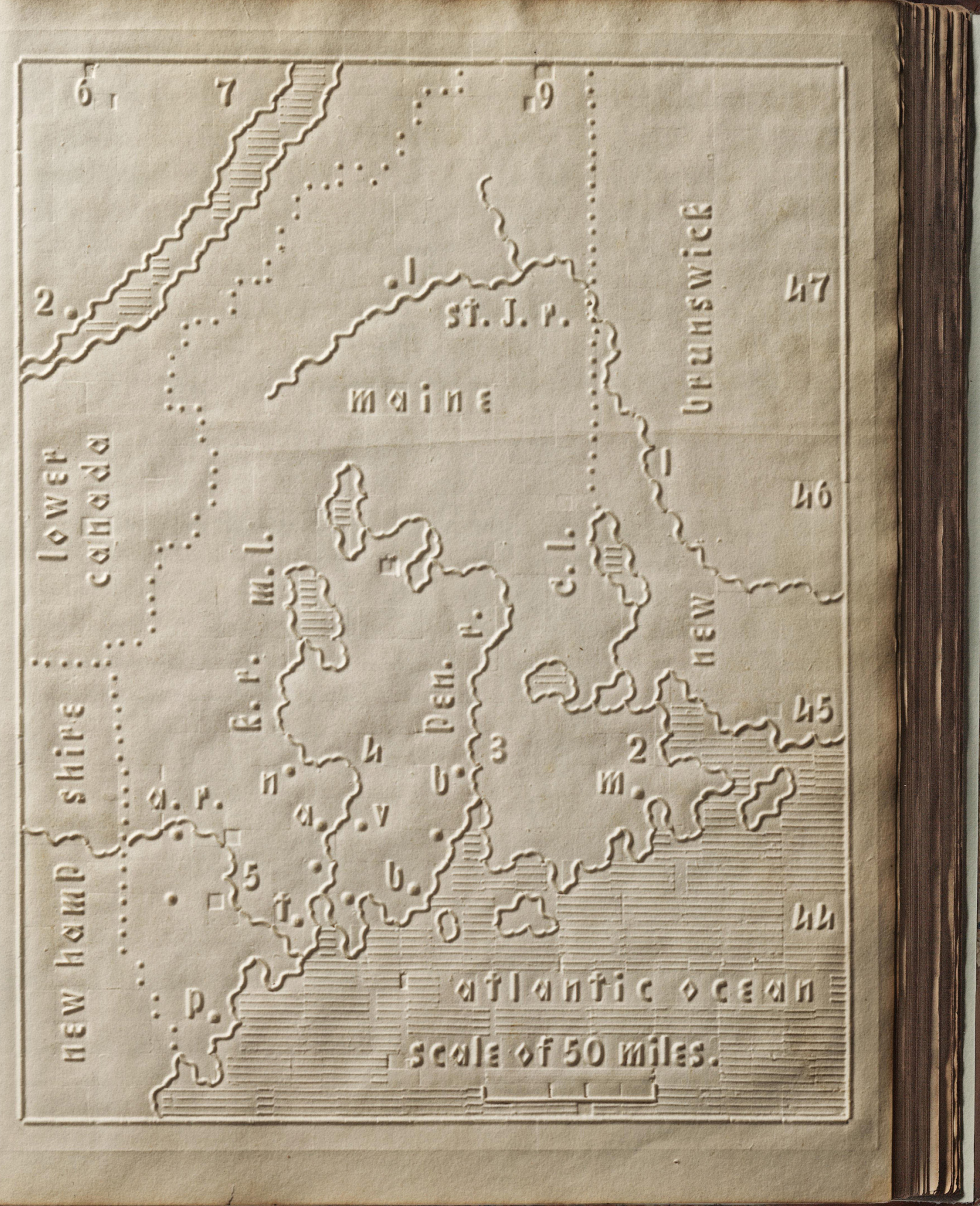

Map of Maine. 
relief and required the assistance of a sighted person. He claimed that his new embossing method was superior in all respects. Today, it is difficult to know how successful the atlas was, although there can be little doubt that these maps helped Howe's blind students visualize geography. We do know that 50 copies were made and five survive today, including one available in the David Rumsey online map collection. The atlas includes 24 state maps with a page of text describing each state and the symbols used on the maps. In our scans, we have lit the maps and text pages from one side to create shadows that reveal the embossing.

The first map in the atlas is of Maine, with dotted lines showing the border with Canada and New Hampshire. Numbers and letters indicate towns, rivers and lakes, and numbers 6 through 9 and 44 through 47 show longitude from Washington DC and latitude. The map shows a scale of 50 miles. All of this and more is explained in the text page for Maine, which follows the map.

Howe wrote about the success of his method of raised relief to teach geography to blind children: "They soon understood that sheets of stiff pasteboard, marked by certain crooked lines, represented the boundaries of countries; rough raised dots represented mountains; pin heads sticking out here and there, showed the locations of towns; or, on a smaller scale, the boundaries of their own town, the location of the meeting-house, of their own and of the neighboring houses, and the like; and they were delighted and eager to go on with tireless curiosity. And they did go on until they matured in years, and became themselves teachers, first in our school, afterwards in a private school opened by themselves in their own town."

Eventually Braille proved more effective than Howe's method of embossed letters, but his maps remain today as wonderful examples of teaching the basic elements of geography and spatial relationships to blind students, enabling them to create the idea of maps as visualizations in their memories. And the Perkins Institute he led continues to teach blind students today, comprising a long and successful record of blind education, including the teaching of Helen Keller.

You can view the entire atlas at davidrumsey.com.

David Rumsey is President of Cartography Associates, a digital publishing company based in San Francisco, and is Chairman of Luna Imaging, a provider of enterprise software for online

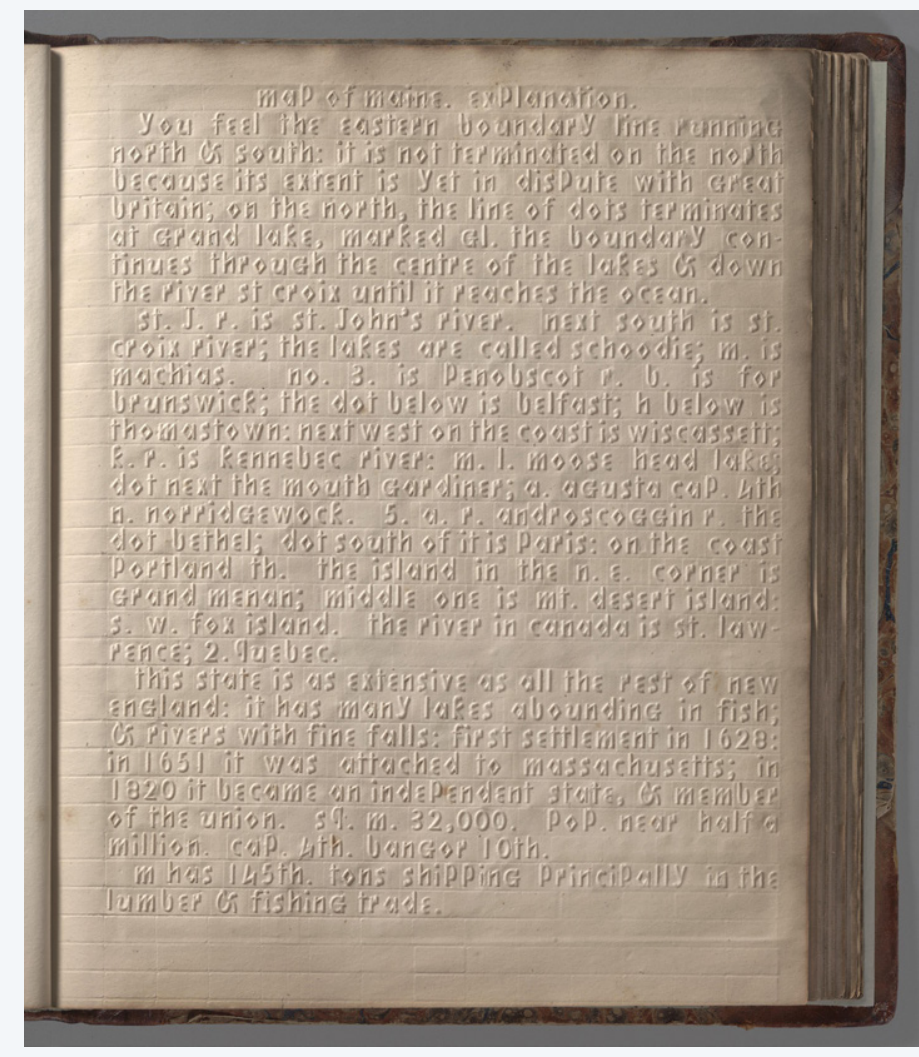

The text page titled "map of maine, explanation" that follows the Maine map.

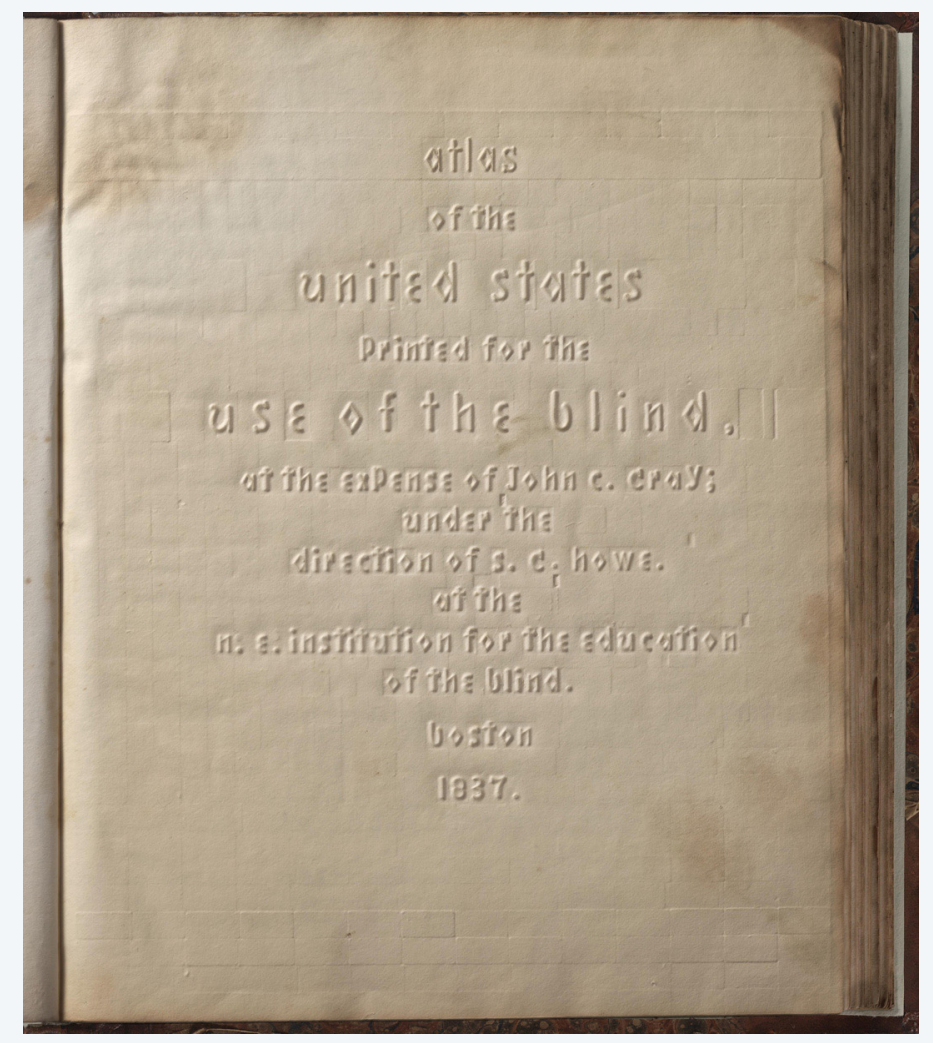

The title page of the atlas. 
image collections. He was a founding member of Yale Research Associates in the Arts, also known as PULSA, a group of artists working with electronic technologies. He subsequently became Associate Director of the American Society for Eastern Arts in San Francisco. Later, he entered a 20 year career in real estate development and finance. Rumsey retired from real estate in 1995 and founded Cartography Associates, beginning a third career as a digital publisher, online library builder, and software entrepreneur.
Rumsey began building a collection of North and South American historical maps and related cartographic materials in 1980. His collection, with more than 150,000 maps, is one of the largest private map collections in the United States. In 1995, Rumsey began the task of making his collection public by building the online David Rumsey Historical Map Collection, www.davidrumsey.com. Currently the online web site has over 64,000 high resolution images of maps from his collection. The site is free to the public and is updated monthly. Recently, Rumsey has been creating historical map projects both in Google Earth, Google Maps and the virtual world of Second Life.

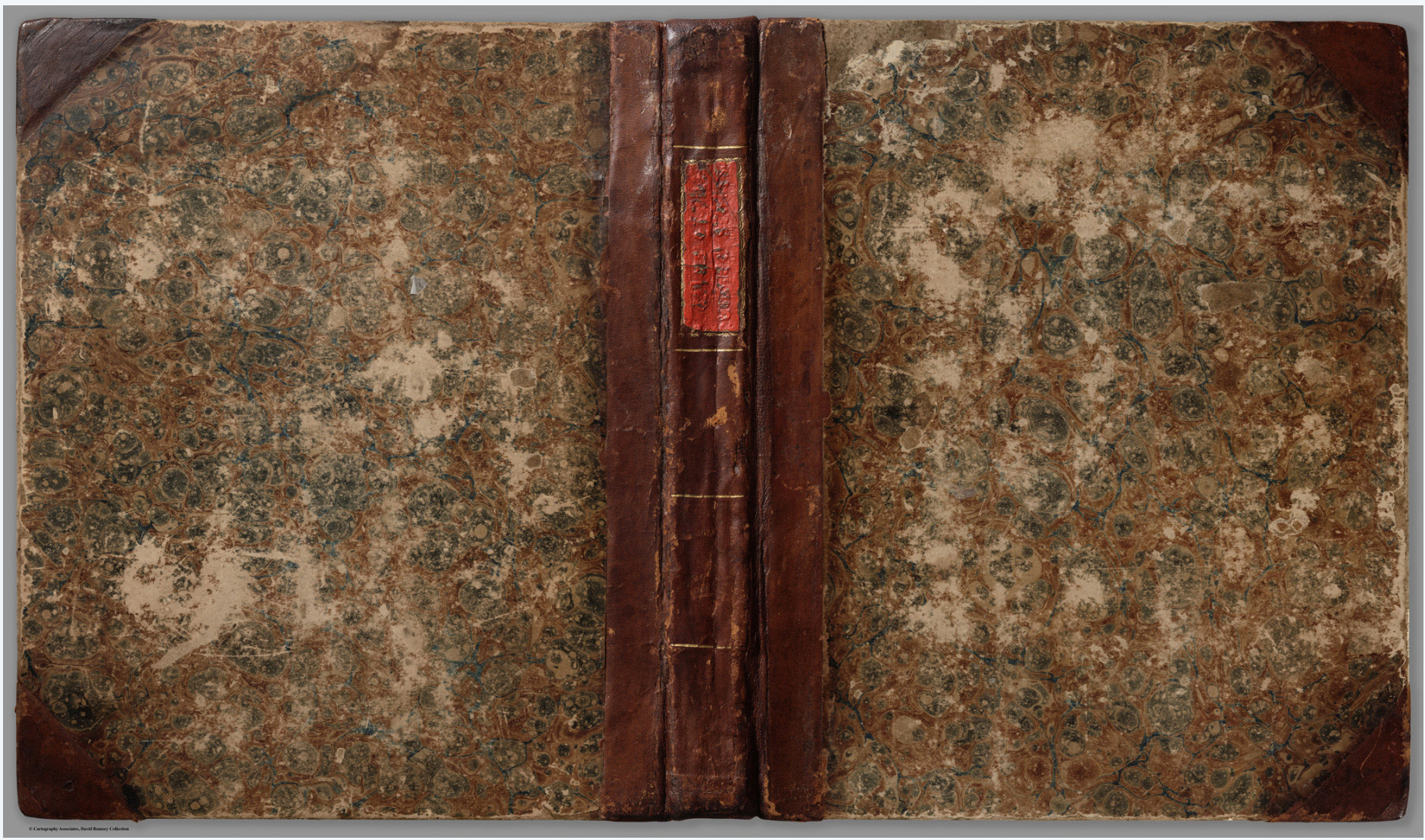

The covers of the atlas. Even the title label on the spine is raised and embossed, saying "Atlas of The United States."

Visual Fields focuses on the appreciation of cartographic aesthetics and design, featuring examples of inspirational, beautiful, and intriguing work. Suggestions of works that will help enhance the appreciation and understanding of the cartographic arts are welcomed, and should be directed to the section editor, Laura McCormick: laura@terracarta.com. 